\title{
Building Bridges, Not Barriers: Inviting Chuukese Family Involvement in Hawaii Schools
}

\author{
Marie Iding, Novia Cholymay and Sandra Kaneshiro \\ University of Hawaii, United States of America
}

\begin{abstract}
C huukese students and parents in Hawaii were interviewed about differences between schools in Hawaii and Chuuk, aspects of schooling in Hawaii that affected adjustment and suggestions for increasing Chuukese family involvement. Differences between schools in Hawaii and Chuuk included availability of materials, different expectations for teachers and students, lack of English language instruction in Chuuk and variable reading background or preparation. Barriers to adjustment to Hawaii schools included limited English proficiency, peer pressure, teachers' negative expectations or prejudice about Micronesian students and ethnic conflicts. Suggestions to facilitate family involvement and make schools more inviting included providing sports clubs for Micronesian students, opportunities for Micronesian students to share about their culture with other students and providing translators at parent-teacher meetings.
\end{abstract}

In Hawaii, media have drawn attention to increased numbers of Micronesian students in Hawaii schools and difficulties students and teachers experience in bridging cultural gaps (Reyes, 2003; Viotti, 2003), particularly for students from Chuuk, ${ }^{1}$ who identified as the Micronesian group most in need of academic assistance (Reyes, 2003). Although Chuukese students are a small but increasing group, with 342 Chuukese speakers in the Honolulu District in 2002 (DOE, 2002), it is important to develop ways to make schools more inviting to them and their families.

Additionally, traditional forms of parental involvement like assisting with homework, 'providing enrichment activities' and volunteering at school functions (HooverDempsey \& Sandler, 1997, pp. 5-6) frequently privilege non-immigrant, native English-speaking, higher socioeconomic status parents, and preclude the involvement of many recent immigrant parents. In fact, as Onikama, Hammond and Koki (1998) argued, family involvement is a more appropriate term for extended Pacific Islander families where child care or guardianship may be distributed among a much larger group than the immediate nuclear family. Finally, we believe it is important to study the perspectives of immigrant groups, such as Chuukese, who are frequently subsumed into larger demographic categories like Pacific Islander that may obfuscate their particular social and economic realities.

Therefore, in the present study, we interview Chuukese students and parents about experiences with Hawaii schools and offer suggestions for ways to increase family involvement and make school experiences as effective and inviting as possible.

\section{Method \\ Participants}

Nine students ( 5 females, 4 males) and four parents ( 3 females, 1 male) were interviewed. The students' ages ranged from 11 to 17 years, with lengths of time in the United States from 1.5 months to 7 years. Parents' lengths of time in the United States ranged from 1 to 10 years.

\section{Data Collection and Analysis}

Semistructured, audiotaped interviews encompassed demographics, comparisons between schools in Hawaii and Chuuk, adjustments to Hawaii schools, suggestions for making schools more inviting and for increasing parental involvement. Interviews conducted in English or Chuukese were transcribed. Two authors discussed and identified general themes that emerged, and independently coded five interviews. The authors 
further discussed and refined the coding scheme and one author coded the remaining interviews according to the general scheme.

\section{Results}

The following sections correspond to the major themes that emerged.

\section{Theme 1: Comparisons of Educational Experiences in Hawaii and Chuuk}

Participants discussed differences between schools in Hawaii and in Chuuk. One major difference was the relatively recent shift from a subsistence lifestyle to a cash economy in Chuuk that has enabled many Chuukese to see the value of formal education. As Alice (a parent) explained:

Before, Chuukese don't want their children to go to school, because they only want them to stay home and do the house chores and other responsibilities... . Beginning during my husband and [my] generation, that is when Chuukese parents started to let the children to go to school, because they finally realise how important education is for the children when money first introduce into the islands.

Of course, the transition to this belief is not universal in Chuuk. This is underscored by the high proportion of people $(17.8 \%)$ who do not receive an education at all (Chuuk State Census Report, 2000), and by the lack of jobs in Chuuk. As a result, many parents bring their children to Hawaii for better educations, although their children might have had limited experiences with formal education when they arrive in Hawaii.

Parents who participated in the interviews also described some other differences between Hawaii schools and schools in Chuuk. For example, in Chuuk, a classroom may only have students and the teacher, without textbooks, a situation that is the case in many developing parts of the world.

In contrast, parents and students describe advantages to Hawaii's schools, including the wide range of course offerings, opportunity to learn English, exposure to students and others from many different cultural backgrounds and new social experiences. An advantage that may be surprising to many Hawaii educators is learning to read. As Krystal explained, 'When I came here I find it hard with reading, since I don't really learn about reading back home'. Krystal was 14 and had been in the United States for 5 years. The variable ages at which students learn to read in Chuuk was an aspect described in previous research (Iding Cholymay, Skouge, \& Peter, in press).

\section{Theme 2: Chuukese Parental Roles}

One of the parents we interviewed, Alice, was a graduate student in Hawaii. In the interview, she acknowledged that the extent of her education gave her a different perspective on parental involvement issues. It is also inter- esting that her perspective about traditional Chuukese views of parental involvement pre-immigration, versus her own current views, appeared to parallel some of the distinctions made by Hoover-Dempsey and Sandler (1997) in discussing school as 'separate' from home (associated with lower socioeconomic status) versus the 'interconnected' model associated with upper class parents (Lareau, 1987, 1989). In other words, it appears that parents with less 'cultural capital' (i.e., less money, education, fluency in English; Bourdieu, 1977) may appear to subscribe to the school as separate perspective. As Alice explained, 'As parents [in Chuuk] we pushed our children to go to school, give them food to eat and make them go to school, but many times we don't know what our children are learning from the school ....'

Additionally, two participants mentioned that Chuukese parents traditionally encourage their children through stories (highlighting the importance of oral traditions), both in Chuuk and in Hawaii. As Alice stated, 'There is this Chuukese saying, "luuluu aaw, kiikii aaw", meaning feed your children food and but also feed your children words'. Clearly, although schools may be viewed as separate, children are nonetheless encouraged to do well.

Alice described a dramatic shift in her parental involvement in Hawaii. We can safely assume that her background as an educator and her experiences in graduate school have facilitated her current interconnected' approach:

The very first day of school when my children started in their school, I make sure my husband and I learn what the schools are offering to my children, so we accompany our children going to school, and go to the office and ask questions based on what courses are offered and how our children could be enrolled and many questions that we need to learn about the schools.

\section{Theme 3: Barriers to Adjustment in Hawaii Schools}

Students and parents noted numerous adjustments to Hawaii schools, including language issues, peer pressure, teachers' prejudice and ethnic conflicts/bullying. Each of these areas is described in more detail below.

Language. The primary barrier for all participants was language. Not being able to speak or understand English was associated with embarrassment, not only with native English speakers, but also with other Chuukese. Unfortunately, teachers (probably unwittingly) added to the difficulty. One student, Brad (age 17), described being unfairly accused of not listening when he asks teachers for clarification. Parents, too, are limited in their participation in school events by language, especially as one parent described, in feeling that their spoken language is inadequate compared to a higher level of proficiency in understanding English. 
Peer pressure. Like other adolescents, Chuukese students are faced with peer pressure challenges. Brad (age 17) described having been friends with older boys who influenced him to devalue school, chew tobacco and betel nut. At this point, he began to flunk his classes. However, Brad did not explain how he came to separate himself from this particular peer group and value his educational experiences, a potentially interesting topic for further research.

Teachers' prejudice/negative expectations. Although all acknowledged teachers' helpfulness, they sometimes felt that teachers acted upon negative stereotypes of 'Micronesian students', a general category that obfuscated their cultural identities as Chuukese. As Elizabeth (age 17) explained,

I find learning difficult with the teacher, because for instance when one Micronesian kid [does] bad, then they think that all the Micronesians are all bad. So they treat us kind of different from the rest of the students at the school. It is not all teachers though only some.

Generally, we feel that teachers do not set out to act in prejudicial or discriminatory fashions, nor are they sometimes even aware that they are doing so. Therefore, an approach that involves teachers learning more about the specific cultures subsumed under the general category 'Micronesian' would be valuable.

Ethnic conflicts and bullying. Students described conflicts with other groups, such as Hawaiians, although it is unclear whether they referred to ethnic Hawaiians or to local Hawaii students, a more general category encompassing many ethnicities. There have also been conflicts with Samoan students (another immigrant group), although one interviewee described this situation as improving. In addition to ethnic conflict, a parent recounted persistent bullying of her son at an elementary school. When she instructed him to report the bullying to teachers, 'My son said that when he talks to the teachers they seem not to listen to him but they would rather listen to the Hawaiian/Samoan boys since they speak fluent English but not my son'.

\section{Theme 4: Suggestions for Ways Schools can Build Bridges}

Students and parents had a variety of suggestions for ways to build bridges between schools, Chuukese students and families. Several students suggested providing opportunities for Chuukese or Micronesian track and field to increase parental and student involvement. Another student suggested setting up active Micronesian clubs at schools. Benefits of such activities include developing social ties and building pride. Potential disadvantages could include unintended segregation by ethnic groups and exacerbations of ethnic divisions, rather than the development of friendships across ethnic groups.

To prevent such outcomes, schools can set up situations where all interested students can participate in activities like track and field at more social, rather than highly competitive, athletic levels.

In addition to these suggestions, students also wanted opportunities to share about their culture, particularly on the schools' cultural days, so that others would better understand Micronesian culture and students. We believe that such an approach would be valuable for other students as well as for teachers.

Students also made suggestions for improving education for Micronesian students. These included providing reading programs and recruiting or training more Micronesian teachers.

Finally, students were asked about ways to increase family involvement. Two students, both adolescents, suggested that parents call teachers regularly, a surprising concept, given adolescent strivings for independence.

Parents made additional suggestions about ways to increase their own involvement in the schools. One parent suggested that increasing parental involvement would be best accomplished by involving church groups, as in Micronesian communities in Hawaii churches serve as the central social structure. Although this is not a traditional approach, it could be quite effective and might also be viable for other Pacific Islander immigrant groups that are socially organised around churches.

Finally, one of the most powerful suggestions was a simple one: to provide translators at parent-teacher meetings. This suggestion may also reflect a lack of awareness of resources that can be requested by parents and teachers in Hawaii's schools.

\section{Conclusion}

Barriers to student adjustment included limited English proficiency, peer pressure, teachers' negative expectations of Micronesian students and ethnic conflicts. Suggestions for facilitating family involvement included providing sports activities and opportunities for cultural sharing and translation for parent-teacher conferences. Implementing these suggestions, in addition to increasing teachers' awareness of the distinct and different cultures encompassed by the term 'Micronesian', would make Hawaii schools much more inviting for Chuukese students and families and show that their input is valued. Finally, investigating school adjustment and family involvement among new, comparatively small immigrant groups in Pacific Islands can contribute to the creation of more effective educational experiences for all in multicultural settings such as Hawaii's schools.

\section{Endnote}

1 Chuuk is one of the Federated States of Micronesia, an independent Pacific Island state, formerly under United States trusteeship. 


\section{References}

Bourdieu, P. (1977). Outline of theory and practice. London: Cambridge University Press.

Chuuk Branch Statistics Office. (2002). Chuuk State Census Report: 2000 FSM Census of Population and Housing. Weno, Chuuk: Government of the Federated States of Micronesia.

Hawaii Department of Education, Honolulu District. (2002). Micronesian student data, SY 2001-2002. Honolulu, HI: Author.

Hoover-Dempsey, K.V., \& Sandler, H.M. (1997). Why do parents become involved in their children's education? Review of Educational Research, 67(1), 3-42

Iding, M., Skouge, J., Cholymay, M., \& Peter, J. (in press). Building literacy-rich environments in the Pacific: College students and literacy in Chuuk, FSM. Pacific Educational Research Journal.

Lareu, A. (1987). Social class differences in family-school relationships: The importance of cultural capital. Sociology of Education, 60, 73-85.

Lareu, A. (1989). Home advantages: Social class and parental involvement in elementary education. New York: Falmer Press.

Onikama, D.L., Hammond, O., \& Koki, S. (1998). Family involvement in education: A synthesis of research for Pacific educators. Retrieved December 13, 2004, from http://www.prel.org

Reyes, B.J. (2003, August 25). Micronesians in need of state services. Honolulu Star-Bulletin, p. A3.

Viotti, V. (2003, October 11). Micronesians, schools strive to bridge gaps. The Honolulu Advertiser, p. A3. 